\title{
Dampak Kinerja Guru PAI terhadap Hasil Pembelajaran al- Quran di Sekolah Menengah Pertama
}

\author{
Erika Yulia Putri \\ Program Pascasarjana Universitas Muhammadiyah Sumatera Barat \\ erikayf@gmail.com
}

\begin{abstract}
This researcher aims to describe the following: the form of pai teacher performance in junior high school, the picture of the results of Qur'an learning students in junior high school and the impact of Islamic Education Teacher performance on the learning results of students in junior high school. The type of research used in this study is a type of field research that uses qualitative descriptive methods, which describes a research result that matches the data found in the field, research data obtained through interviews, observations and documentation, data processed and analyzed and inferred. This research managed to find: 1) The form of pai teacher performance in junior high school is its important role in helping students face or solve their difficulties in Qur'an learning, 2) the picture of qur'an learning results of students in Junior High School still encounters many difficulties in understanding makhraj, mad and tajwid. 3) The impact of PAI Teacher's performance on the learning outcomes of students in junior high school is the increasing results of Qur'an learning students or by improving the quality of reading of students and it turns out that the better the performance of PAI teachers will have a better impact on the learning results of Qur'an Learners.
\end{abstract}

Keywords: performance, learning outcomes, Qur'an

\begin{abstract}
Abstrak
Penelitian ini bertujuan untuk mendeskripsikan hal sebagai berikut: bentuk kinerja guru PAI di Sekolah Menengah Pertama, gambaran hasil pembelajaran Alquran peserta didik di Sekolah Menengah Pertama dan dampak kinerja Guru Pendidikan Agama Islam terhadap hasil pembelajaran peserta didik di Sekolah Menengah Pertama. Jenis penelitian yang digunakan dalam penelitian ini adalah jenis penelitian lapangan atau field research yang mana disini menggunakan metode deskriptif kualitatif, yaiitu menggambarkan sebuah hasil penelitian yang sesuai dengan data yang ditemukan di lapangan, data penelitian didapatkan melalui wawancara, observasi dan dokumentasi, data diolah dan dianalisis dan disimpulkan. Penelitian ini berhasil menemukan: 1) Bentuk kinerja Guru PAI di Sekolah Menengah Pertama adalah peran pentingnya dalam membantu peserta didik menghadapi atau memecahkan kesulitan mereka dalam pembelajaran Alquran, 2) gambaran hasil
\end{abstract}


pembelajaran Alquran peserta didik di Sekolah Menengah Pertama masih banyak menemui kesulitan pada pemahaman makhraj, mad dan tajwid. 3) dampak kinerja Guru PAI terhadap hasil belajar peserta didik di Sekolah Menengah Pertama adalah meningkatnya hasil pembelajaran Alquran peserta didik atau dengan meningkatnya kualitas bacaan peserta didik dan ternyata semakin bagus kinerja guru PAI akan berdampak lebih bagus pada hasil pembelajaran Alquran Peserta didik.

Kata Kunci: kinerja guru, hasil pembelajaran, Alquran

\section{Pendahuluan}

Guru dalam melaksanakan tugasnya dituntut untuk selalu bersungguhsungguh dan tanggap terhadap perubahan dan perkembangan yang ada dalam bidang pendidikan". Maka dari itu guru dituntut agar lebih baik lagi dan meningkatkan kompetensinya yang akan mempengaruhi peningkatan kinerjanya. Ketika guru mempunyai kompetensi yang bagus, kinerja gurupun cenderung akan meningkat kearah yang lebih baik $^{2}$. Alquran merupakan pegangan dan pedoman utama untuk umat Islam ${ }^{3}$, karena Alquran adalah merupakan sumber ajaran Islam yang memuat seluruh aspek kehidupan berupa aqidah, akhlak, ibadah, sejarah dan sosial.

Pengajaran awal Alquran dapat diperoleh oleh anak di rumahnya sendiri yang ditangani oleh orang tua sebagai pengajar dan pendidik pertama bagi anak ${ }^{4}$. Selanjutnya anak akan mendapat pendidikan dan pengajaran di lembaga-lembaga pendiidikan, dalam hal ini ada yang bentuk lembaga pendidikan formal maupun nonformal yang akan ditangani oleh Guru PAI.

Kenyataan yang berada di masyarakat saat ini berada pada 2 keadaan yang berlawanan/berbeda, yaitu kondisi masyarakat yang telah menyadari pentingnya membaca Alquran sebagai langkah awal dalam memahami kandungan Alquran dan

1 Tisnelly, Mahyudin Ritonga, and Aguswan Rasyid, "Kompetensi Guru Pendidikan Agama Islam Madrasah Ibtidaiyah Negeri 1 Pasaman Barat Pasca Sertifikasi," Rubama: Islamic $\begin{array}{llllll}\text { Education Journal } & 3, & \text { no. } & 1 & \text { (2020): }\end{array}$ https://doi.org/https://doi.org/10.31869/ruhama.v3i1.1940.

2 Maulidarni, Murniati, and Niswanto, "Implementasi Manajemen Strategik Dalam Meningkatkan Kinerja Guru Pada SD Unggulan Iqro Sigli," Jurnal Magister Administrasi Pendidikan Pascasarjana Universitas Syiah Kuala 6, no. 2 (2018): 92-97.

${ }^{3}$ Nurlaili, Mahyudin Ritonga, and Mursal, "Muroja'ah Sebagai Metode Menghafal AlQur'an Studi Pada Rumah Tahfiz Yayasan Ar-Rahmah Nanggalo Padang," Menara Ilmu XIV, no. 02 (2020): 73-82.

${ }^{4}$ Rosniati Hakim et al., "Implementation of Contextual Teaching and Learning in Islamic Education at Madrasah Diniyah," Journal of Advanced Research in Dynamical \& Control Systems 12, no. 02 (2020): 3326-32, https://doi.org/10.5373/JARDCS/V12I2/S20201455. 
kemudian menerapkan ajaran-ajaran yang terkandung di dalamnya ${ }^{5}$. Sehingga banyak masyarakat yang mengikuti pengajian dan banyak pula para orang tua yang memasukkan putra-putrinya ke lembaga pendidikan Islam, seperti MI, MTs, MA, Pesantren ataupun TPA dengan harapan putra-putri mereka memperoleh pendidikan agama yang memadai ${ }^{6}$, terlebih khusus lagi mampu membaca Alquran dengan baik dan benar.

Kondisi lain yang terdapat di masyarakat adalah masih banyaknya masyarakat yang belum menyadari pentingnya membaca Alquran sehingga mereka mengesampingkan pendidikan agama dan malas belajar Alquran. Hal ini juga terjadi pada kalangan pelajar, tidak sedikit pelajar Islam yang masih malas untuk belajar Alquran. Sebagai dampaknya, mereka mengalami kesulitan dalam Alquran dan karena kesulitan itulah membuat minat baca tulis Alquran pelajar menurun. Pada umumnya kesulitan yang banyak ditemui adalah masih banyak peserta didik yang gugup membaca Alquran, baik dari segi makhraj, kelancaran pembacaan maupun pemahaman tajwid yang kurang. Hal ini juga dialami oleh peserta didik di SMPN 2 V Koto Timur yang terletak di Kabupaten Padang Pariaman.

Dari beberapa pernyataan diatas penulis merasa masalah ini penting untuk dibahas dalam sebuah karya ilmiah yang dapat dikonsumsi oleh para kalangan akademisi dan sebagai referensi bagi SMPN $2 \mathrm{~V}$ Koto Timur. Untuk itu dalam artikel akan dideskripsikan beberapa hal, yaitu bagaimana bentuk kinerja guru PAI, bagaimana gambaran hasil pembelajaran Alquran peserta didik dan bagaimana dampak kinerja guru PAI terhadap hasil pembelajaran peserta didik di SMPN $2 \mathrm{~V}$ Koto Timur.

\section{Metodologi Penelitian}

Untuk menyelesaikan permasalahan penelitian sebagaimana dijelaskan di atas, penelitian ini dirancang dengan menggunakan penelitian kualitatif. Tempat penelitian dilakukan di Sekolah Menengah Pertama Negeri $2 \mathrm{~V}$ Koto Timur Pariaman, waktu penelitian berlangsung selama 4 bulan, yakni sejak November 2019 sampai dengan Feruari 2020.

Sumber data penelitian ialah meliputi kepala sekolah, pengawas dan peserta didik serta guru pendidikan agama Islam. Penetapan informan ini dikarenakan bahwa merekalah yang mampu untuk memberikan informasi tentang apa yang diharapkan. Adapun teknik yang digunakan dalam mengumpulkan data ialah observasi, waawancara dan studi dokumentasi. Data yang telah dikumpulkan berdasarkan tekniknya kemudian dianalisis sesuai dengan pendekatan kualitatif, yakni reduksi data, klasifikasi, dan interpretasi.

${ }^{5}$ Mohd Aderi Che Noh et al., "The Study of Quranic Teaching and Learning: United Kingdom," Mediterranean Journal of Social Sciences 5, no. 16 (2014): 313-17, https://doi.org/10.5901/mjss.2014.v5n16p313.

6 Ahmad Lahmi et al., "Internet, Pesantren and Management Strategies Educational Building," International Journal of Advanced Science Research 29, no. 4 (2020): 2827-36, http://sersc.org/journals/index.php/IJAST/article/view/23459/12133. 


\section{Hasil dan Pembahasan}

\section{Bentuk Kinerja Guru Pendidikan Agama Islam di SMP Negeri V Koto Timur}

Sekolah Menengah Pertama Negeri 2 V Koto Timur didirikan pada tahun 2005, identitas sekolah ini waktu itu adalah SMPN SATAP (Satu Atap) V Koto Timur, saat itu kita masih numpang belajar di SDN 16 V Koto Timur. Tahun 2006 kita dapat bantuan bangunan dari pemerintah, dan tahun 2007 kita sudah bisa belajar di gedung sendiri lanjut tahun 2008 kita resmi dengan SMPN 2 V Koto Timur hingga sekarang. SMPN $2 \mathrm{~V}$ Koto Timur terletak di Jl. Padang Alai Malalak, Korong Koto Tinggi, Nagari Gunung Padang Alai, Kecamatan V Koto Timur, Kabupaten Padang Pariaman.

Lembaga pendidikan ini berdiri di atas tanah seluas 2.952 meter bujursangkar, terdiri dari satu ruang kepala sekolah yang menyatu dengan perpustakaan, satu ruang guru, tiga ruang belajar terdiri dari kelas VII, kelas VIII dan kelas IX, satu ruang labor IPA lengkap dengan perlengkapannya, halaman yang sekaligus menjadi lapangan upacara bendera dan lapangan olahraga, ada perlengkapan olahraga, ada 20 Alquran, di utara bangunan sekolah ada bangunan mesjid raya Koto Tinggi. SMPN $2 \mathrm{~V}$ Koto Timur ini sudah terakreditasi C. Di Sekolah ini terdapat 28 orang peserta didik laki-laki dan 8 orang peserta didik perempuan yang sudah merupakan jumlah dari 5 orang kelas VII, 12 orang kelas VIII dan 11 orang kelas I serta 14 guru Bidang studi.

Dari hasil wawancara dengan guru PAI, Kepala Sekolah dan peserta didik serta observasi, penulis menemukan simpulan bahwa bentuk kinerja guru PAI yang dapat dilihat adalah peran pentingnya dalam membantu peserta didik menghadapi atau memecahkan kesulitan mereka dalam pembelajaran Alquran. Guru melakukan membantu peserta didik mengatasi kesulitan mereka dalam membaca Alquran dengan cara yang lembut, guru PAI mendekati peserta didik yang kesulitan atau yang masih salah dalam membaca Alquran dan mengajarinya dengan perlahan. Guru PAI menggunakan teknik yang sangat apik, ia mengajari peserta didik dengan penuh kelembutan dan dengan gaya yang disukai oleh peserta didik sehingga ilmu yang disampaikan mudah dicerna oleh peserta didik. Guru PAI menggunakan metode Qira'ah dan metode Iqra' dalam memperbaiki cara baca Alquran peserta didik,selain itu guru PAI juga mengarahkan agar peserta didik mengulang-ulang bacaan sesering mungkin.

Seorang informan menjelaskan bahwa sudah banyak mengajarkan saya tentaang Alquran, sebelumnya saya hanya bisa membaca Alquran tanpa tajwid dan tanpa makhraj. Mendengar saya saat membaca Alquran beserta tjwidnya yang salah, guru PAI menegur saya dan mengajarkan saya tentang hukum tajwid serta pembacaannya yang benar.sekarang saya sudah paham tentang 3 tajwid yaitu izhar, ikhfa dan iqlab. Guru PAI juga menyarankan saya rutin membaca Alquran setiap 
hari di rumah agar lebih cepat lancar. Saya juga dapat giliran membaca Alquran di kelas sekali seminggu dan di lapangan sekali 2 bulan.begitu pernyataan randi saat saya temui di kelas.

Hal ini sesuai dengan apa yang penulis temukan di lapangan ketika observasi, penulis menemukan guru PAI sedang mengajarkan cara baca Alquran yang baik dan benar saat jam istirahat di ruang guru. Penulis juga menemukan setiap kelas membaca Alquran setiap pagi di lapangan dan sebelum proses pembelajaran dimulai. Teknik penyampaian yang lembut akan lebih cepat dipahami oleh peserta didik. Selanjutnya adalah gambaran hasil pembelajaran Alquran peserta didik, dari hasil wawancara dengan guru PAI, Kepala Sekolah dan peserta didik serta observasi pertama, dapat penulis simpulkan bahwa prestasi peserta didik masih jauh dari yang diharapkan dan secara garis besar kesulitan-kesulitan yang dihadapi peserta didik dalam membaca Alquran adalah dalam makhraj dan tajwid, mereka masih banyak yang belum paham dengan makhraj dan tajwid. Hal ini disebabkan oleh kurangnya arahan dari guru PAI yang lama dan kurangnya kerja sama dari orang tua peserta didik.

Untuk langkah selanjutnya guru harus memberikan arahan, mengajari dengan metode yang tepat, perlu latihan supaya lancar membaca Alquran dan perlu perhatian khusus serta bimbingan dari orang tua peserta didik. Menurut kepala sekolah semula dari 28 orang peserta didik tercatat $60 \%$ peserta didik yang bisa baca Alquran tapi tidak lancar, 25\% yang lancar dan sisanya hanya mengenal huruf hijaiyah. Akan tetapi setelah kita berganti guru agama sejak awal tahun pelajaran lalu, Alhamdulillah kondisinya sudah mulai membaik, dari yang tidak lancar sudah mulai lancar, dari yang tidak bisa sudah berangsur bisa baca Alquran. Sejauh ini belum ada kendala berarti yang ditemukan oleh guru baru kita di kelas. Disisi lain, yang menjadi masalah bagi peserta didik dalam pembelajaran Alquran adalah tidak ada dukungan, perhatian dan kerja sama dari oran tua peserta didik.

Para orang tua sepertinya hanya mengharapkan sekolah mendidik anakanak mereka. Padahal kerjasama orang tua dalam membimbing dan mendidik peserta didik adalah hal yang sangat penting dalam perkembangan peserta didik. Makhraj, seperti pengucapan huruf $\varepsilon$ masih diucapkan dengan pengucapan huruf !, pengucapan huruf $\mathbf{\theta}$ dan huruf $\dot{\mathcal{C}}$ masih diucapkan dengan makhraj $\underline{\underline{j}}$, pengucapan huruf $\underline{b}$ masih dibaca dengan makhraj $\stackrel{\Xi}{*}$ pengucapan huruf $\underline{ش}$ diucapkan dengan pengucapan $\underset{\omega}{\omega}$, pengucapan huruf $\boldsymbol{ح}$ masih diucapkan dengan pengucapan huruf $\underline{\bullet}$, pengucapan huruf $\underline{\boldsymbol{b}}$, dan huruf $\underline{\mathfrak{j}}$ masih diucapkan dengan makhraj $\underline{j}$, pengucapan huruf $\stackrel{ث}{=}$ masih dibaca dengan makhraj w, pengucapan huruf ص diucapkan dengan pengucapan س ش ش dan begitupun sebaliknya.

Pada bagian tajwid, masih banyaknya pembacaan Alquran tanpa tajwid, sebagian besar dari mereka masih tidak paham tentang tajwid, namun ada juga yang sudah bisa menempatkan tajwid yang benar akan tetapi tidak kenal nama tajwidnya. Disini masih banyak terdapat kesalahan peserta didik dalam penempatan mad yang pas. Dikelas VII masih ada yang salah dalam penempatan Harakat, seperti harkat 
dhammah mereka baca dengan harakat sukun, harkat fathah mereka baca dengan harkat kasrah, harkat kasrah mereka baca dengan harkat fathah, begitu sebaliknya. Bahkan masih ada beberapa diantara mereka yang belum mengenal huruf hijaiyah, dalam arti masih belum bisa merangkai huruf hijaiyah.

Berbeda dengan kelas VII, di kelas VIII hasil observasi penulis menemukan sebagian kecil dari peserta didik kelas VIII sudah sangat paham tentang keluar bunyi huruf yang baik dan benar, sebagian yang lain sudah mulai paham tentang makhraj. Meski begitu, diantara mereka masih ada yang benar-benar belum paham tentang beberapa pengucpan huruf yang baik dan benar. Sama halnya den kelas VII, di kelas delapan ini masih banyak yang belum paham tentang tajwid, belum kenal dengan hukum hukum tajwid. Sebagian besar dari mereka sudah mengenal mad, akan tetapi dalam pengaplikasiannya pada bacaan masih belum pas.

Lain halnya dengan kelas VII dan kelas VIII, kelas IX memiliki kemampuan yan lebih baik dalam pembelajaran Alquran, meskipun masih ada yang kurang, di kelas IX, pengucapan huruf yang baik sudah dapat mereka pahami, pengucapan huruf sudah keluar dengan bunyi yang seharusnya. Jikapun ada yang kurang pas, hanya sebagian kecil saja, karena pada umumnya mereka sudah bisa mengucapkan huruf dengan baik. Sebagian besar peserta didik kelas IX sudah bisa mengaplikasikan tajwid dengan baik pada saat membaca Alquran, mereka sudah mengenal tajwid dan cara mengaplikasikannya meskipun kadang masih ada yang kurang pas.

Mad memang hal yang agak sulit mengukurnya bagi pembaca Alquran yang baru lancar, begitu pula lah yang terjadi pada kelas IX. Mereka sudah paham mad, akan tetapi dalam pengaplikasiannya mereka masih kurang pas. Dengan kondisi pemahamaman mereka tetang bacaan Alquran yang masih kurang serta membaca Alquran yang masih terbata-bata, dalam menghafal Alquran mereka masih suka merubah tulisan Alquran ke huruf latin, alasan mereka mereka adalah supaya mudah dan cepat dalam mengejar target hafal Alquran yang menjadi syarat mutlak mengikuti ujan Akhir. Begitu halnya yang disampaikan oleh seorang peserta didik yag bernama Meri bahwa dia bersama teman-temannya merubah tulisan dalam Alquran ke huruf latin agar mudah membaca dan cepat menghafalnya.

Mengajarkan Alquran dibutuhkan kemampuan yang baik dari setiap pengajarnya ${ }^{7}$, karena Alquran sebagai kalamullah jika diajarkan oleh orang yang tidak memiliki kemampuan yang baik akan berdampak pada ketidaksesuaian dengan isi kandungan Alquran yang dimaksud ${ }^{8}{ }^{-9}$. Berdasarkan pernyataan ini diketahui

7 Alhamuddin et al., "Developing Alquran Instruction Model Through 3A (Ajari Aku AlQuran or Please Teach Me Al-Quran) to Improve Students' Ability in Reading AL-QUran at Bandung Islamic University," International Journal of Education 10, no. 2 (2018): 95-100.

${ }^{8}$ Reni Fauziah, Mahyudin Ritonga, and Fitri Alrasi, "Korelasi Tsiqah Tahfidz Al-Qur'an Dengan Maharah Al-Lughah Al-'Arabiyyah Mustawa Tsalits Ma'had Az-Zubair Bin Al-Awwam," EL-TSAQAFAH Jurnal Jurusan PBA 19, no. 1 (2020): 25-36, https: journal.uinmataram.ac.id/index.php/eltsaqafah\%0AKORELASI. 
bahwa mengajarkan tajwid kepada peserta didik adalah bagian dari mengajarkan Alquran.

\section{Hasil Belajar Alquran di Sekolah Menengah Pertama Negeri V Koto Timur}

Sesuai dengan hasil penelitian, data yang terkait dengan hasil belajar ALquran di Sekolah Menengah Pertama Negeri V Koto Timur ialah dapat dilihat pada table 1, 2, dan 3 seperti di bawah ini:

Tabel 1. Hasil Belajar Alquran Kelas VII SMP Negeri Koto Timur

\begin{tabular}{|l|l|l|}
\hline No. & Nama & Nilai \\
\hline 1. & Yosi Triana & 7,3 \\
2. & Rina Apri & 7,8 \\
3. & Andri & 7,0 \\
4. & Sintia & 6,5 \\
5. & Murni & 6,7 \\
6. & Aziz & 4,6 \\
7. & Atira & 5,8 \\
8. & Cintana & 6.9 \\
9. & Radit & 5,2 \\
10. & Farel & 8,2 \\
11. & Nindya & 7,7 \\
12. & Cahaya & 4,9 \\
\hline
\end{tabular}

Tabel 2. Hasil Belajar Alquran Kelas VIII SMP Negeri Koto Timur

\begin{tabular}{|l|l|l|}
\hline No. & Nama & Nilai \\
\hline 1. & Yosi Triana & 8,0 \\
2. & Rina Apri & 8,5 \\
3. & Andri & 7,9 \\
4. & Sintia & 7,8 \\
5. & Murni & 8,8 \\
6. & Aziz & 8,9 \\
7. & Atira & 7,8 \\
8. & Cintana & 8,5 \\
9. & Radit & 7,8 \\
10. & Farel & 7,7 \\
11. & Nindya & 8,2 \\
12. & Cahaya & 8,7 \\
\hline
\end{tabular}

Tabel 3. Hasil Belajar Alquran Kelas XIV SMP Negeri Koto Timur

${ }^{9}$ Fitria Sartika and Mahyudin Ritonga, Redesain Kurikulum TPQ/MDTA Sebagai Lembaga Pendidikan Informal Dalam Membentuk Generasi Muslim, ed. Mahyudin Ritonga (Padang: UMSB Press, 2020). 


\begin{tabular}{|l|l|l|}
\hline No. & Nama & Nilai \\
\hline 1 & Halim & 7,9 \\
2 & Ulfah & 8,0 \\
3 & Dinda & 8,2 \\
4 & Mutia & 8,5 \\
5 & Tiara & 8,5 \\
6 & Bobi & 7,7 \\
7 & Rifki & 7,8 \\
8 & Ego & 7,8 \\
9 & Randa & 7,8 \\
10 & Mesintya & 8,7 \\
11 & Abral & 7,9 \\
\hline
\end{tabular}

Dari data di atas diketahui bahwa hasil belajar Alquran di Sekolah Menengah Pertama Negeri $2 \mathrm{~V}$ Koto masih banyak yang berada pada criteria ketuntasan minimal. Namun hasil ini sesuai dengan yang dijelaskan oleh guru PAI diketahui bahwa sudah mengalami peningkatan, hasil wawancara ini juga sesuai dengan dokumen yang ada, diketahui pada dokumen terdapat 15 (lima belas) orang peserta didik yang belum mencapai ketuntasan minimal.

Hasil pembelajaran di atas sesuai dengan temuan penelitian yang dilakukan oleh Togatorop dan Heryanto yang mengaskan bahwa kinerja guru mempengaruhi hasil pembelajaran, ${ }^{10}$ hasil temuan penelitian ini juga mendukung hasil analisis yang dilakukan oleh Manullang yang mengatakan bahwa kinerja guru memiliki pengaruh yang besar terhadap peningkatan hasil pembelajaran ${ }^{11}$. Dari temuan di atas dapat dinyatakan bahwa guru pendidikan agama Islam yang memiliki kinerja bagus sangat dibutuhkan, hal ini ditegaskan oleh Rusdan dan kawan-kawan ${ }^{12}$ yang mengatakan bahwa menghadapi era revolusi industri menuntut kemampuan yang tinggi dari guru pendidikan agama Islam.

\section{Dampak Kinerja Guru PAI terhadap Hasil Pembelajaran Alquran di SMP Negeri 2 V Koto}

Dampak kinerja guru PAI terhadap hasil pembelajaran peserta didik, Untuk mencapai tujuan yang diinginkan dalam proses pembelajaran bukan suatu hal yang mudah karena berbagai komponen terkait didalamnya, seperti pengetahuan guru tentang cara menghadapi peserta didik, mengelola kelas, kompetensi yang harus

${ }^{10}$ Jainal B. Togatorop and Heryanto, "The Effect of Teacher Performance on Student Learning Outcomes Public Elementary School 060934 Medan Johor Academic Year 2017/2018,” International Journal of Education, Learning and Development 7, no. 5 (2019): 97-107.

11 Resi Adelina Manullang, "Pengaruh Kinerja Guru Terhadap Hasil Belajar Siswa Di SMP Negeri 4 Tanjung Jabung Timur Kota Jambi,” Jumal Ilmiah Universitas Batanghari Jambi 17, no. 3 (2017): 1-6.

12 Ayu Hidayati Rusdan, Ahmad Lahmi, and Aguswan Rasyid, "Kompetensi Profesional Guru Pendidikan Agama Islam Dalam Menghadapi Tantangan Era Revolusi Industri 4.0 (Studi Komparatif Di SMP Se Kecamatan Lembah Melintang Kabupaten Pasaman Barat)," Rubama: Islamic Education Journal 3, no. 1 (2020): 9-23. 
dimiliki dan lain-lain. Oleh karena itu penulis memulai bab ini dari perangkat pembelajaran, penulis melihat RPP guru PAI terkait Materi pembelajaran Alquran.

Penulis melihat, membaca dan memperhatikan RPP tersebut masih berbentuk RPP lama, belum tersentuh dengan pembaharuan, baik dari segi tampilan, penulisan maupun komponen-komponen yang tertulis di dalamnya. Menurut penulis, tidak ada salahnya melakukan pembaharuan pada RPP, missal dari segi penulisan bisa ditata agar lebih indah, komponen misalnya pada metode, boleh ditambahkan dengan metode lain, menyesuaikan materi dengan metode akan lebih efektif dampaknya pada proses pembelajaran dan hasil belajar. Meskipun RPP jauh dari sempurna, guru PAI di SMPN 2 V Koto Timur berhasil dalam pelaksanaan pembelajaran.

\section{Penutup}

Guru PAI mampu menguasai kelas dengan baik, mampumenciptakan komunikasi baik dengan peserta didik, mampu mengatur pendekatan yang cocok untuk masing-masing peserta didiknya, mampu memilih dan menggunakan metode yang pas untuk materi yang akan disampaikannya, hal ini penulis temukan saat penulis melakukan observasi ke lapangan tepatnya ketika guru PAI mengajar. Dari hasil wawancara dan hasil observasi, maka kinerja guru PAI yang baru mampu memberi dampak positif pada hasil pembelajaran Alquran Peserta didik di SMPN 2 V Koto Timur. Sudah jelaslah bahwa semakin bagus kinerja seorang guru akan berdampak bagus pula pada hasil belajar peserta didik, hal itu tak terkecuali pada PAI khususnya pada pembelajaran Alquran. Saat pembelajaran Alquran diampu oleh guru PAI yang kurang berkompetensi dan dengan kinerja yang kurang bagus akan berdampak kurang bagus pula pada hasil belajar peserta didik. Sebaliknya, ketika pembelajaran Alquran diampu oleh guru yang berkompetensi dan dengan kinerja yang bagus makan akan berdampak bagus pula hasil belajar peserta didik.

\section{Referensi}

Alhamuddin, Fahmi Fatwa Rosyadi Satria Hamdani, Dikdik Tandika, and Rabiatul Adwiyah. "Developing Alquran Instruction Model Through 3A (Ajari Aku Al-Quran or Please Teach Me Al-Quran) to Improve Students' Ability in Reading AL-QUran at Bandung Islamic University." International Journal of Education 10, no. 2 (2018): 95-100.

Fauziah, Reni, Mahyudin Ritonga, and Fitri Alrasi. "Korelasi Tsiqah Tahfidz AlQur'an Dengan Maharah Al-Lughah Al-'Arabiyyah Mustawa Tsalits Ma'had Az-Zubair Bin Al-Awwam." EL-TS AQAFAH Jurnal Jurusan PBA 19, no. 1 (2020): 25-36.

https: journal.uinmataram.ac.id/index.php/eltsaqafah\%0AKORELASI.

Hakim, Rosniati, Mahyudin Ritonga, Khadijah, and Wetti Susanti. "Implementation of Contextual Teaching and Learning in Islamic Education at Madrasah Diniyah." Journal of Advanced Research in Dynamical \& Control Systems 12, no. 02 (2020): 3326-32. https://doi.org/10.5373/JARDCS/V12I2/S20201455.

Lahmi, Ahmad, Mahyudin Ritonga, Riki Saputra, Mursal, Sandra Ayu, Talqis 
Nurdianto, and Surya Afdhal. "Internet, Pesantren and Management Strategies Educational Building." International Journal of Advanced Science $\begin{array}{llll}\text { Research 29, } & \text { 2020): }\end{array}$ http://sersc.org/journals/index.php/IJAST/article/view/23459/12133.

Manullang, Resi Adelina. "Pengaruh Kinerja Guru Terhadap Hasil Belajar Siswa Di SMP Negeri 4 Tanjung Jabung Timur Kota Jambi.” Jurnal Ilmiah Universitas Batanghari Jambi 17, no. 3 (2017): 1-6.

Maulidarni, Murniati, and Niswanto. "Implementasi Manajemen Strategik Dalam Meningkatkan Kinerja Guru Pada SD Unggulan Iqro Sigli." Jurnal Magister Administrasi Pendidikan Pascasarjana Universitas Syiab Kuala 6, no. 2 (2018): 92-97.

Noh, Mohd Aderi Che, Ab. Halim Tamuri, Khadijah Abd. Razak, and Asmawati Suhid. "The Study of Quranic Teaching and Learning: United Kingdom." Mediterranean Journal of Social Sciences 5, no. 16 (2014): 313-17. https://doi.org/10.5901/mjss.2014.v5n16p313.

Nurlaili, Mahyudin Ritonga, and Mursal. "Muroja'ah Sebagai Metode Menghafal AlQur'an Studi Pada Rumah Tahfiz Yayasan Ar-Rahmah Nanggalo Padang.” Menara Ilmu XIV, no. 02 (2020): 73-82.

Rusdan, Ayu Hidayati, Ahmad Lahmi, and Aguswan Rasyid. "Kompetensi Profesional Guru Pendidikan Agama Islam Dalam Menghadapi Tantangan Era Revolusi Industri 4.0 (Studi Komparatif Di SMP Se Kecamatan Lembah Melintang Kabupaten Pasaman Barat).” Ruhama: Islamic Education Journal 3, no. 1 (2020): 9-23.

Sartika, Fitria, and Mahyudin Ritonga. Redesain Kurikulum TPQ/MDTA Sebagai Lembaga Pendidikan Informal Dalam Membentuk Generasi Muslim. Edited by Mahyudin Ritonga. Padang: UMSB Press, 2020.

Tisnelly, Mahyudin Ritonga, and Aguswan Rasyid. "Kompetensi Guru Pendidikan Agama Islam Madrasah Ibtidaiyah Negeri 1 Pasaman Barat Pasca Sertifikasi." Ruhama: Islamic Education Journal 3, no. 1 (2020): 45-56. https://doi.org/https://doi.org/10.31869/ruhama.v3i1.1940.

Togatorop, Jainal B., and Heryanto. "The Effect of Teacher Performance on Student Learning Outcomes Public Elementary School 060934 Medan Johor Academic Year 2017/2018." International Journal of Education, Learning and Development 7, no. 5 (2019): 97-107. 